\title{
Cancer Awareness in Malawi: A Comprehensive Analysis of News Coverage on Mass Media
}

\author{
Flemmings Fishani Ngwira1,2* ${ }^{1}$, Bin Zuo $^{2}$, Jessie Mkandawire3, Wellman Kondowe4 \\ ${ }^{1}$ Department of Language and Communication, University of Malawi, The Polytechnic, Blantyre, Malawi \\ ${ }^{2}$ School of Psychology, Central China Normal University, Wuhan, China \\ ${ }^{3}$ School of Public Health and Family Medicine, College of Medicine, University of Malawi, Zomba, Malawi \\ ${ }^{4}$ Department of Language and Literature, Mzuzu University, Mzuzu, Malawi \\ Email: ^fishaningwira@gmail.com
}

How to cite this paper: Ngwira, F. F., Zuo, B., Mkandawire, J., \& Kondowe, W. (2020). Cancer Awareness in Malawi: A Comprehensive Analysis of News Coverage on Mass Media. Advances in Journalism and Communication, 8, 117-130.

https://doi.org/10.4236/ajc.2020.84009

Received: July 10, 2020

Accepted: December 5, 2020

Published: December 8, 2020

Copyright $\odot 2020$ by author(s) and Scientific Research Publishing Inc. This work is licensed under the Creative Commons Attribution-NonCommercial International License (CC BY-NC 4.0). http://creativecommons.org/licenses/by-nc/4.0/ (c) (i) \& Open Access

\begin{abstract}
Cancer has become one of the major public health problems in Malawi and its incidence is increasing at an alarming rate. Mass media plays an essential role in influencing the public's awareness and perception of cancer. The present study analyzed cancer related news articles in two leading weekend newspapers: "The Nation" and "Malawi News" published in 2019, and health programs from two radio stations: "Malawi Broadcasting Cooperation" (radio 1) and "Zodiac", and two Television stations from the same media companies. Out of 106 newspapers reviewed, only 38 (36\%) had cancer-related articles. Content analysis of news articles revealed that focus was on breast cancer with 8 (53\%) articles. Kaposi sarcoma, cervical and oesophagus cancers, which have the highest morbidity in Malawi, were under-reported; with 1 (6.6\%), 1 (6.6\%) and $0(0 \%)$ articles respectively. In addition, prevention was the most frequently mentioned theme with treatment, early detection, signs and symptoms, and risk factors mentioned only rarely. Except during awareness month of breast cancer, where a program was aired once on radio and TV stations, there were no specific programs set aside for cancer in their health programs. The findings suggest that apart from breast cancer, which appears to be influenced by its awareness month, media coverage of cancer appears under-represented. Possible implications of the results and recommendations for future research are presented.
\end{abstract}

\section{Keywords}

Cancer, Awareness, Mass Media, News Coverage, Communication

\section{Introduction}

Malawi is a low-income sub-Saharan country with an approximate population of 
18 million, and over $50 \%$ of the population is estimated to live below the international poverty line of 1.25 USD per day (The World Bank, 2018). Like many developing countries in the sub-Saharan region, Malawi has already suffered the burden of communicable diseases such as HIV/AIDS, Tuberculosis and Malaria. The situation makes it a challenge to manage some non-communicable diseases such as cancer, and as a result, cancer incidence rates increase in the country (Gyorki, Muyco, Kushner, Brennan, \& Kingham, 2012; Masamba, 2015). The Malawi National Cancer Registry (NCR) conducted a nationwide cancer registry to find out new cancer cases registered between 2007 and 2010. The report indicates that among female patients, cervical cancer was the commonest type accounting to $45.4 \%$ of all the registered cases, followed by Kaposi sarcoma (21.1\%), cancer of the oesophagus (8.2\%), breast cancer (4.6\%) and non-Hodgkin lymphoma (4.1\%). Among male patients, Kaposi sarcoma was the commonest accounting to $50.7 \%$, followed by cancer of the oesophagus (16.9\%), non-Hodgkin lymphoma (7.8\%), prostrate (4.0\%) and urinary bladder (3.7\%). In both genders, the top three common cancer cases appeared to be Kaposi sarcoma (34\%), cervical cancer (25\%) and oesophagus (12\%; Msyamboza et al., 2012).

The burden of cancer in Malawi is overwhelming. Statistically, oncologists have expressed their concerns on the increase of cancer prevalence. For instance, at Kamuzu Central Hospital (KCH) cancer unit in Lilongwe, a referral hospital in central Malawi, about 1500 cases were registered in 2015 (Nkhoma, 2015), and at Queen Elizabeth Central Hospital (QECH), a referral hospital in southern Malawi, a minimum of ten new cases of cancer were being registered in a day (Mughogho, 2015). On cervical cancer alone, it is estimated that about 3684 cases are diagnosed annually, of which 2314 die from the disease annually (Bruni et al., 2016). Globally, in 2012, Malawi had the highest cervical cancer age-standardized incidence rate of 75.9/100,000 and the world wide highest oesophagus cancer age-standardized incidence rate of 24.2/100,000 (Ferlay et al., 2014). Kaposi sarcoma continues to cause high morbidity and mortality rates among both men and women in Malawi; it accounts for up to 34\% of all cancers, the majority of which are among HIV-infected people (Mwafongo et al., 2014). With this high cancer incidence rates in the country, there is a great need to emphasize our communication approach on its prevention and early diagnosis in order to mitigate the burden of cancer care in the hospitals.

One of the major contributors to the biggest cancer management challenge in Malawi is lack of awareness. A number of studies have indicated that people are not aware of the disease; they have limited knowledge of its warning signs and risk factors (Chadza et al., 2012; Oleniacz, 2016). Due to this lack of awareness, most women delay or never go for their cervical and breast cancer screening services (Chadza et al., 2012; Kapindu, 2016). Delays in seeking cancer medical care consequently escalate cases where people seek medical care during its terminal stage, that is, after signs and symptoms have developed (Gyorki et al., 2012; Nkhoma, 2015; Kapindu, 2016). On average, for every 10 people who go to the hospital, eight of them are always in a critical condition which cannot be treated 
in Malawi (Nyasa Times, 2013). Research indicates that when cancer is diagnosed early, that is, before it has the chance to get too big or spread, it is more likely to be treated successfully (Etzioni et al., 2003; Chadza et al., 2012). Awareness of cancer warning signs and risk factors is vital in cancer prevention; people are able to take actions towards their health protection. Research shows that mass media plays an essential role in influencing the public's awareness and perception of cancer (Aggarwal, Batura, \& Sullivan, 2014).

Mass media can be described as channels of communication capable of relaying the message to a large number of people. In Malawi, common mass media communication channels include televisions, radios and newspapers. Messages on mass media enjoy a large coverage. Each channel has its own advantages that make it attract a large mass of people. Together, mass media manages to reach the country's widely dispersed, heterogeneous audience. Because it is a cheap, simple, portable and ubiquitous medium of mass communication, the radio has highly been regarded as a powerful source of information world-wide (Okorie, 2011). Furthermore, especially in Malawi where electricity is hardly available and very epileptic in its supply, the radio enjoys wide coverage because it is not limited to electricity power supply alone. Television also possesses unique capacity of presenting audio-visual programs. Therefore, it is capable of showing vivid information through its characteristics of sound, sight and motion displayed simultaneously. The print media, particularly newspapers, have two major advantages of permanence and the possibility of information custody and storage for close reading and future use (Okorie, 2011). Consequently, the public can access information at any time they are free, and can even read the information repeatedly for their own understanding.

Regarding health, mass media can become an important ally, playing a linking role between health promotion advocates and the public. Because of its wide reach, cost effectiveness and message simplicity, mass media has emerged to be an effective way in persuading mass audiences to adopt new behaviors, or in reminding them of critical information about health (Naveena, 2015). Furthermore, given that most people, especially in the rural areas do not meet medical professionals regularly (Konfortion, Jack, \& Davies, 2014; Miyawaki, Shibata, Ishii, \& Oka, 2017), mass media remains a valuable means of raising public awareness and knowledge of health information. For public awareness to occur, the audience must be exposed to the information, attend to it, comprehend it, and act on it (Flora, Maibach, \& Maccoby, 1989; Catalán-Matamoros, 2011). Acquiring knowledge is a necessary condition for an attitudinal change which further leads to subsequent health behaviors. The role of mass media on health is to adequately air or distribute clear health messages that capture audiences" attention for them to act on the information.

Research on cancer awareness indicates that obtaining cancer information has shown to be positively associated with knowledge of cancer, its preventive and protective measures (Miyawaki et al., 2017). In addition, the dissemination of cancer information might also play a critical role in public awareness across the 
continuum of cancer (prevention, detection, diagnosis, prognosis, treatment and end of life). Research reports inconsistent results on the mass media coverage of cancer messages. For instance, some studies found that the media focused their news coverage on certain types of cancers, not even linked to cancer incidence or mortality (Konfortion et al., 2014; Miyawaki et al., 2017); some focused on certain topics within the continuum of cancer care such as treatment (Jensen, Moriarty, Hurley, \& Stryker, 2010; Miyawaki et al., 2017) and not on prevention. These varying findings on news coverage simply suggest that any country's political, social and cultural aspects can influence mass media's coverage of cancer messages. It was, therefore, important to analyze how mass media cover these cancer messages in Malawi where such analyses are scanty.

The present study, therefore, was designed to analyze mass media cancer news coverage in terms of cancer types, the continuum of cancer care, cancer risk factors, and signs and symptoms. Three specific questions guided the current study:

1) How often do the mass media in Malawi discuss different types of cancer?

2) How do the mass media in Malawi discuss the continuum of cancer care?

3) How do the mass media in Malawi report risk factors warning signs of cancer?

\section{Methods}

\section{Design}

The study used "mixed methods" design to analyze mass media cancer news coverage in Malawi. According to Wisdom and Creswell (2013), the term "mixed methods" refers to an emergent methodology of research that advances the systematic mixing of quantitative and qualitative data within a single investigation or sustained program of inquiry. The study used content analysis to quantitatively analyze contents of messages in newspapers and thematic analysis to qualitatively analyze contents of messages on radio and TV stations. Qualitative data was obtained through in-depth interviews which were conducted with the officials from the radio and TV stations.

\section{1) Sample and procedure}

Newspaper article data for this study were drawn from the two leading weekend newspapers: "The Nation" and "Malawi News". The two chosen newspapers are those with the highest circulation in Malawi, and the sample included all weekend articles published between the first weekend of January and the last weekend of December, 2019. Data were obtained from College of Medicine's library's news archive services. All newspapers published within the year, 2019, containing cancer-related articles were sampled for the content analysis; other newspapers which did not meet the inclusion criteria were left out. Radio and TV newscast data were obtained through in-depth interviews with officials from two media stations: Malawi Broadcasting Cooperation, which is a state-owned institution, and Zodiac, which is a private broadcasting institution. All interview items were on cancer-related health programs and newscasts broadcasted in the 
year, 2019. The recorded data were transcribed verbatim for coding and analysis.

\section{2) Coding variables}

\section{Cancer type}

Regarding cancer type variable, coders identified all cancer types discussed in the news articles and in-depth interview scripts. News articles and interview scripts that mentioned specific types of cancer were coded according to the types discussed. With reference to the cancer statistics in the country (Msyamboza et al., 2012), the identified and recorded cancer types included Kaposi sarcoma, cervical, oesophagus and breast cancers. Other types including leukemia, lymphoma, lung and childhood cancers were coded as "others".

\section{Cancer continuum}

Another aspect we looked at was the discussion of the entire continuum of cancer care. According to Kreps $(2003,2012)$, the continuum of cancer care includes prevention, detection and diagnosis, treatment and end-of-life care. Therefore, coders noted which aspects of the continuum of cancer care were discussed as major topics in the news. Specifically, the continuum aspects included prevention (including information to promote awareness); early detection and diagnosis (including information to promote cancer screening); treatment (including information about the available treatments); and end of life (including palliative care messages).

Cancer risk factors and signs

Risk factors of cancer are any aspects of one's life that can increase the risk of developing cancer in an individual. On risk factors, coders identified whether a news article or a script mentioned any of the five common risk factors according to Jensen et al. (2010): life style, environmental, demographic, medical and genetic. Life style risk factors included tobacco consumption and sexual activity; environmental factors included chemical and occupational hazards; demographic factors included age and socioeconomic status; and finally, medical factors included viruses such as HPV and other infections. Genetic had no further category. On warning signs, coders indicated whether the article had some common signs and symptoms or not.

\section{3) Coding and data analysis}

The study recruited three coders to work on the interview scripts and news articles; they reviewed the articles and selected only the ones which met the inclusion criteria. For reliable coding and theme identification, the analysis began with an independent reading, coding, and categorizing themes from the articles and the interview scripts. After the individual coding, analysts brought together their analysis results to identify overarching themes. Divergences in interpretations across the three analysts were reconciled at a group level review; this interactive process continued until coders reached a general consensus. For the content analysis, descriptive statistics which included frequencies and percentages were calculated using Microsoft excel to show patterns of news coverage in the media. For qualitative thematic analysis, transcribed audio data were entered in an NVivo 11 qualitative data analysis software for coding and theme identifica- 
tion. After reaching a consensus, overarching themes were now ready for reporting.

\section{Results}

Out of 106 newspapers reviewed, the present study identified only 38 (36\%) newspapers which had cancer-related articles, with wider coverage taken from the weekend Malawi news (36) representing $94.7 \%$ of the included articles. It was discovered that most cancer-related news articles in the weekend Malawi news were from an organization called "Think Pink Malawi" which has a page in the newspaper on cancer awareness. As for the radio and TV broadcasts, interviews were conducted with six officials (3 from $\mathrm{MBC}$ radio 1 and TV stations, 3 from Zodiac radio and TV stations). Except during awareness month of breast cancer, where a program was aired once on radios and TV stations, there were no specific programs set aside for cancer in their health programs. The study further discovered some challenges that the media face in broadcasting health-related messages.

\subsection{Newspapers}

Content analysis of news articles in terms of topics covered in the news items revealed that focus was on the continuum of cancer care with 37 (54.4\%) occurrences describing different aspects of cancer care. This was followed by the discussions on different types of cancer with 15 (22.0\%) occurrences. The least to be discussed were the risk factors and the signs and symptoms of cancer with 8 (11.7\%) occurrences each. As for the continuum of cancer care, prevention was the most frequently mentioned aspect of the continuum with treatment, early detection and diagnosis, and end-of-life mentioned only rarely. In addition, on cancer types, the analysis revealed that focus was on breast cancer with 8 (53\%) occurrences. Kaposi sarcoma, cervical and oesophagus cancers, which have the highest morbidity in Malawi, were under-reported. Table 1 illustrates the coverage frequencies and percentages for each sub-category in details.

Table 1. Frequencies of cancer topic coverage in newspapers.

\begin{tabular}{|c|c|c|c|}
\hline Variable & Sub-category & Frequency & Percentage \\
\hline \multirow{5}{*}{ Cancer types } & 1) Kaposi sarcoma & 1 & $6.6 \%$ \\
\hline & 2) Cervical cancer & 1 & $6.6 \%$ \\
\hline & 3) Oesophagus cancer & 0 & $0.0 \%$ \\
\hline & 4) Breast cancer & 8 & $53.3 \%$ \\
\hline & 5) Others & 5 & $33.3 \%$ \\
\hline \multirow{4}{*}{ Continuum } & 1) Prevention & 17 & $45.9 \%$ \\
\hline & 2) Early detection/diagnosis & 8 & $21.6 \%$ \\
\hline & 3) Treatment & 9 & $24.3 \%$ \\
\hline & 4) End of life & 3 & $8.1 \%$ \\
\hline
\end{tabular}




\begin{tabular}{lccc} 
Continued & & & \\
\hline & 1) Life style & 4 & $50.0 \%$ \\
2) Environmental & 2 & $25.0 \%$ \\
Risk factors & 3) Demographic & 1 & $12.5 \%$ \\
& 4) Medical & 1 & $12.5 \%$ \\
Signs and symptoms & 5) Genetic & 0 & $0.0 \%$ \\
\hline
\end{tabular}

\subsection{Radio and TV Stations}

The analysis of in-depth interviews, which was conducted to find out about cancer news on radio and TV stations, revealed different themes regarding cancer news coverage.

\subsubsection{Cancer Programs}

Almost all the four broadcasting stations agreed on the fact that they did not have a specific health program that discusses cancer. Cancer enjoyed full coverage in these radio and TV stations during the awareness months, and this comes once in a year for just a few types. One participant (official 1) from MBC radio 1 and TV stations emphasized that the two media houses did not have a specific cancer program aired at the stations but could feature stories about cancer in their news bulletin.

Basically, we do not have a specific program at MBC radio (1) and TV stations to do with cancer. Usually such type of issues are featured as news stories in our news bulletins, sometimes such cancer issues are talked as topics in programs such as "speak out" but I can't really tell how often we do that, its random.

Another participant from Zodiac radio station (official 2) indicated that:

Apart from the three-minute-long promotional messages on cervical cancer, which had repeatedly been aired since 2014, whose main content is on treatment and advocacy for screening, there are no specific health programs for cancer.

\subsubsection{Cancer Types}

Breast cancer and cervical cancer are the types of cancer that somewhat enjoyed the coverage on radio and TV stations. Other types such as Kaposi sarcoma and lung cancers were found to be under-represented. From Zodiac radio and TV stations, one participant (official 3) indicated that the only type which, at a certain point, enjoyed good coverage was breast cancer.

I remember since 2016, we have had a breast cancer awareness week which we cover messages about breast cancer for the whole week, aired once a day. You know, here at Zodiac radio station for instance, we have a health program which is aired twice a week, on Saturday and a repeat on Wednesday. Talking about other types $[$ of cancer $]$... mmm ... they are discussed rarely.

At $\mathrm{MBC}$ radio 1 and TV stations, one official (official 1) indicated that mostly, cervical cancer and breast cancer are the common aired types of cancer on their 
broadcast stations. From Zodiac TV, the participant (official 5) did not indicate any preference on the commonest featured type of cancer; he said the incidence for each type is very random.

\subsubsection{Cancer Topics}

It was difficult to identify which aspect of cancer continuum enjoyed coverage on radio and TV stations. Officials had different stories to say, which clearly shows that there were no clear patterns of the topics discussed. However, during breast cancer awareness week, almost all aspects of breast cancer continuum were discussed. This was found to be common in all the broadcasting stations this research covered. For instance, one participant (official 2) from Zodiac radio indicated that "as for breast cancer awareness week, we cover almost every aspect of the disease including prevention, signs and symptoms, risk factors and treatment". This statement further agrees with what the other participant (official 1) from MBC radio 1 and TV stations said:

During breast cancer awareness period, our stations cover almost all topics as long as the information is available. During other times where cancer is being featured on our health programs, I can't really say either prevention or treatment enjoys a wider coverage. However, since the first lady (the wife of the state president) is taking a leading role on encouraging women to go for cancer screening, I can say, consequently, prevention and screening aspects enjoy a rather wider coverage.

\subsubsection{Challenges}

One theme which inductively emerged from the data was the "challenges" these media houses faced in featuring cancer-related newscasts. The first challenge was lack of funding. It seems there could be enough airtime to slot in programs that could discuss cancer-related issues but due to lack of funding, these issues did not have enough coverage. One participant (official 4) from $\mathrm{MBC}$ radio 1 said: "there is enough airtime to slot in such cancer-related programs, with the available funding, there could be a 15 -20-minute cancer program to be aired at some point in a week". From Zodiac radio station, one participant (official 2) said: "currently we have no funding for health programs and during the cancer awareness week, we use our own money as a radio station". From MBC TV another participant (official 6) said: "there is no funding for cancer-related programs and news material collection at the institution, if we had enough funding for air time and material collection, there could be an improvement in as far as cancer message dissemination is concerned".

The second challenge was on information resource. At Zodiac, one participant (official 3) lamented: "there is a problem when we want to source the information from the ministry of health; maybe now, things might go well with the partnership that we are in". From MBC TV, another participant (official 6) indicated that getting information from the health sector is a hassle, "there is a lot of bureaucracy in the medical sector when it comes to sourcing information". 
This suggests that with such difficulties, it becomes hard for the media to broadcast a wide range of cancer topics.

\section{Discussion}

The present study aimed to identify media coverage of cancer-related news in 2019. Results indicate that generally, cancer is under-reported. For instance, out of the 106 reviewed newspapers, only 38 (36\%) had cancer-related articles, and all the four broadcast stations (2 radio and 2 TV stations) reported not having any specific program where cancer could be featured. This is an indication that Malawi's mass media do not regularly publish or broadcast cancer-related messages throughout the year. These results are consistent with findings from other previous studies which also found that cancer was heavily under-represented in the media considering its high incidence and mortality rate (Williamson, Jones, \& Hocken, 2011; Konfortion et al., 2014). Mass media can play an important role in influencing the public's awareness and perception of cancer, but if the messages are not regular enough, the role might be jeopardized. Stryker, Moriarty and Jensen (2008) discovered that there was a positive relationship between frequency of cancer news coverage and knowledge of cancer one could demonstrate. This implies that the more one is exposed to cancer messages, the more knowledgeable he/she becomes. According to Catalán-Matamoros (2011) and Okorie (2011), this knowledge eventually leads to behavioral change towards health protection. Therefore, it is desirable for the media in Malawi, through newspaper houses, radio and TV stations, to regularly report cancer messages.

With the few newspapers that reported cancer-related news, and a few occurrences of cancer news on radio and TV stations, the study revealed that there were some disparities in reporting cancer types. Consistent with findings from several previous studies (Slater, Long, Bettinghaus, \& Reineke, 2008; Konfortion et al., 2014; Jensen et al., 2010), breast cancer dominated mass media coverage. The reason for such dominance is not apparent. Surprisingly, breast cancer is not amongst the top types of cancers that have high morbidity and mortality rates among women in Malawi (Msyamboza et al., 2012). The reason for this dominance might be due to its effective marketing models used by breast cancer communication planners. As it has been observed, radio and TV stations mostly featured breast cancer on their health programs during the breast cancer awareness week. This might mean that breast cancer received a considerable amount of funding to be featured on radio and TV stations. More importantly, it should also be noted that most cancer-related news articles in the weekend Malawi news were from "Think Pink Malawi", an organization which advocates for breast cancer; whose founder, Blandina Mlenga Khondowe, is a breast cancer survivor.

Interestingly, other cancer types such as Kaposi sarcoma, cervical and oesophagus cancers, which have higher morbidity and mortality rates in Malawi than breast cancer, were under-reported. For instance, newspaper analysis revealed that Kaposi sarcoma, cervical and oesophagus cancers were reported in $1(6.6 \%)$, 
$1(6.6 \%)$ and $0(0 \%)$ articles respectively. The results are in line with other studies elsewhere which found that some cancers received much less media attention compared with their incidence and mortality rates (Slater et al., 2008; Cai, Yang, Liu, Ma, \& Liu, 2009; Miyawaki et al., 2017). Apart from cervical cancer, these cancers have no screening programs in Malawi for the media to promote and this could be a major reason why these other cancers are underrepresented in the media. These results suggest that there is a mismatch of media coverage between cancer type, incidence and mortality rates of cancer. Malawi's mass media need to increase coverage of especially the common types for the awareness to be effective. Furthermore, out of the already few articles which had cancer-related messages, only $22 \%$ of the articles featured cancer types, which shows that the majority (78\%) did not include any information about the types. This suggests that these articles provided general information about cancer which could easily be ambiguous. The media should therefore, discuss these specific cancer types and provide evidence-based information in order to mitigate misunderstandings that might arise due to the ambiguousness that might come from the general information.

The cancer continuum received relatively more attention, with 37 (54.4\%) occurrences in newspapers discussing different aspects of cancer care. Content analysis towards the continuum revealed that prevention was the most frequent aspect with 17 (45.9\%) occurrences. This is inconsistent with other previous studies analyzing media coverage of cancer messages (Slater et al., 2008; Jensen et al., 2010; Miyawaki et al., 2017). These studies discovered that treatment was the most frequently discussed aspect of the continuum. In the current study, other aspects such as early detection, diagnosis, treatment and end-of-life were mentioned only rarely implying that the media is not consistent in reporting aspects of the continuum. While it is important to emphasize on prevention for the disease to be dealt with before it affects an individual, in cancer control, other aspects of cancer care are equally vital. For instance, an increase in news coverage about cancer diagnosis and treatment could influence attitudes and perceptions of the public, and consequently manipulate their behavioral towards protecting their health. There is a great need for journalists to balance up news coverage on every aspect of cancer care.

Risk factors and warning signs received the least attention with only 8 (11.7\%) occurrences. These findings are supported by other previous studies (Jensen et al., 2010; Miyawaki et al., 2017); it is problematic for the media to report cancer risk factors. Despite receiving the least attention, the common risk factor discussed in especially newspapers was "life style" with 4 (50\%) occurrences. The news coverage regarding risk factors corresponds well with the current research on cancer care. Most cancer cases are largely attributed to lifestyle choices such as smoking and diet (Kreps, 2008; Petersen, 2009; Jensen et al., 2010). Despite the well-known crucial aspect of lifestyle risk factors on cancer disease, the media should try to balance up all risk factors, with an emphasis on lifestyle, to avoid the audience missing out important aspects on other risks factors. Know- 
ledge of risk factors is a central element in cancer prevention; people become aware of what to avoid or what to do in order to prevent cancer. Equally, although signs and symptoms were mentioned only rarely, knowledge of cancer signs and symptoms is central in early detection and diagnosis. With proper knowledge, people are able to take actions towards their health protection.

The study also discovered that one of the major challenges faced by the media, especially radio and TV broadcasts, was lack of funding. Funding is one of the most important elements that make mass media messages effective. According to literature, two significant aspects of message delivery on mass media are 1) control over message placement and 2) production quality (Catalán-Matamoros, 2011). Control over message placement ensures the audience's exposure to the message due to the right timing and frequency of the messages placed on the media. This control cannot be assured with donated public service time since the ultimate decision is left to the media schedulers who might place little importance to the messages. With paid programs, placement of messages gets a priority and the audience attains adequate exposure to the messages. Funders in cancer need to take this challenge seriously if we have to register success in cancer control. The other challenge was on information resource. This suggests that it is problematic to get cancer information from the right people, the health personnel. Such intricate information about cancer need to be handled with delicacy, and it is only from the right people that one can get the right information. Failure to do that might lead to misrepresentation of some facts resulting into misunderstanding of the information. Health advocates need to put the right strategies for a better information flow to the media; they need to be available when needed.

\section{Limitations and Further Research}

The current study had some limitations that need to be recognized. First, data for the study were drawn from a single year, 2019, without considering a range of successive years to observe the trend of media cancer news coverage. It might happen that this is an improved trend and that we are going towards the right direction. Further studies should consider including a set of years in their methodology to observe any trend. Second, the study only analyzed two major weekend newspapers, two radio and two TV stations. In Malawi, there are a number of newspapers including "Daily Nation" and "Malawi News", a number of radio stations, and a few TV stations which are also important in disseminating cancer messages to the public. The current results, therefore, might not be generalized beyond the selected sample. Another limitation is that due to the exploratory nature of this study, there was no examination of the content quality of the articles; it only concentrated on the frequency of cancer-related news and some topics on the cancer types, the continuum, risk factors, signs and symbols. Future research should concentrate on more qualitative nature of the messages such as message design, frame and efficacy. 


\section{Implications for Health Promotion}

Limitations aside, the present study found out that cancer-related articles were not reported regularly throughout the year implying that the target audience did not get adequate exposure to the message; regular messages ensures audience' adequate exposure to information. Furthermore, the study discovered that they were some imbalances in reporting cancer types, the continuum and risk factors. For specific cancers, it was also discovered that the proportions of coverage of those specific cancers did not accurately reflect their incidence on morbidity and mortality rates. These findings postulate that there is a substantial room for improvement on cancer news coverage in Malawi. Compared with other types of cancers, the increased mass media coverage of breast cancer during annual awareness periods implies that breast cancer communication planners have effective strategies for their cancer promotion. Other cancer communicators need to examine these strategies and implement the same during other cancer type awareness campaigns. Findings of the present study provide confirmation that mass media is responsive to such awareness messages.

Considering the manipulative role of the media as a source of health information to the public, mass media health communicators need to be encouraged to increase cancer information flow focusing on specific cancers, the continuum, risk factors, signs and symptoms which were under-reported in the present study. Health communicators could also consider the use of social media as an important source of health information. It may have a significant effect on health behaviors in Malawi, especially among the young people. With the problem of information source which the study has established, care should be taken to avoid confusing the audience. Medical personnel and health promotors need to collaborate with journalists to ensure that relevant information is being reported on the media. Funding has also been discovered to be one of the major drawbacks in covering cancer messages in the media. Without funding, it is possible to report cancer messages on media, but message placement and frequency, which are important determiners of audience's adequate exposure to messages, are ultimately left to the media schedulers who sometimes place little significance to the messages. With paid programs, the audience attains adequate exposure to the messages. Therefore, funders in cancer care need to be encouraged to increase funding for the success of cancer prevention and control.

\section{Conflicts of Interest}

The authors declare no conflicts of interest regarding the publication of this paper.

\section{References}

Aggarwal, A., Batura, R., \& Sullivan, R. (2014). The Media and Cancer: Education or Entertainment? An Ethnographic Study of European Cancer Journalists. Ecancermedicalscience, 8,423 . 
Bruni, L., Barrionuevo-Rosas, L., Albero, G., Serrano, B., Mena, M., Gómez, D., Muñoz, J., Bosch, F. X., \& de Sanjosé, S. (2016). Human Papillomavirus and Related Diseases in Malawi. Summary Report, ICO Information Centre on HPV and Cancer (HPV Information Centre). http://www.hpvcentre.net/statistics/reports/MWI.pdf

Cai, J., Yang, L., Liu, Z., Ma, Z., \& Liu, Y. (2009). Comprehensive Analysis of Cancer Coverage in Important Chinese Newspapers between 2000 and 2007. Supportive Care in Cancer, 17, 329-332. https://doi.org/10.1007/s00520-008-0494-1

Catalán-Matamoros, D. (2011). The Role of Mass Media Communication in Public Health, Health Management. In K. Smigorski (Ed.), Different Approaches and Solutions (pp. 399-414). London: InTech. https://doi.org/10.5772/22790 http://www.intechopen.com/books/health-management-different-approaches-andsolut ions/the-role-of-mass-media-communication-in-public-health

Chadza, E., Chirwa, E., Maluwa, A., Malata, A., Kazembe, A., \& Chimwaza, A. (2012). Factors That Contribute to Delay in Seeking Cervical Cancer Diagnosis and Treatment among Women in Malawi. Health, 4, 1015-1022.

https://doi.org/10.4236/health.2012.411155

Etzioni, R., Urban, N., Ramsey, S., McIntosh, M., Schwartz, S., Reid, B., Radich, J., Anderson, G., \& Hartwell, L. (2003). The Case for Early Detection. Nature Reviews Cancer, 3, 1-10. https://doi.org/10.1038/nrc1041

Ferlay, J., Soerjomataram, I., Ervik, M., Dikshit, R., Eser, S., Mathers, C., Rebelo, M., Parkin, D. M., Forman, D., \& Bray, F. (2014). Cancer Incidence and Mortality Worldwide: IARC Cancer Base No. 11 [Internet]. Lyon: International Agency for Research on Cancer. http://www.wcrf.org/int/cancer-facts-figures/data-specific-cancers

Flora, J. A., Maibach, E. W., \& Maccoby, N. (1889). The Role of Media across Four Levels of Health Promotion Intervention. Annual Review of Public Health, 10, 181-201. https://doi.org/10.1146/annurev.pu.10.050189.001145

Gyorki, D. E., Muyco, A., Kushner, A. L., Brennan, M. F., \& Kingham, T. P. (2012). Cancer Surgery in Low-Income Countries. Archives of Surgery, 147, 1135-1140. https://doi.org/10.1001/archsurg.2012.1265

Jensen, J. D., Moriarty, C. M., Hurley, R. J., \& Stryker, J. E. (2010). Making Sense of Cancer News Coverage Trends: A Comparison of Three Comprehensive Content Analyses. Journal of Health Communication: International Perspectives, 15, 136-151. https://doi.org/10.1080/10810730903528025

Kapindu, H. (2016). Think Pink Malawi: Early Cancer Detection Saves Lives. Nyasa Times.

https://www.nyasatimes.com/think-pink-malawi-early-cancer-detection-saves-lives-kh ondowe/

Konfortion, J., Jack, R. H., \& Davies, E. A. (2014). Coverage of Common Cancer Types in UK National Newspapers: A Content Analysis. British Medical Journal, 4, 1-7. https://doi.org/10.1136/bmjopen-2013-004677

Kreps, G. L. (2003). The Impact of Communication on Cancer Risk Incidence, Morbidity, Mortality, and Quality of Life. Health Communication, 15, 161-169. https://doi.org/10.1207/S15327027HC1502_4

Kreps, G. L. (2008). Strategic Use of Communication to Market Cancer Prevention and Control to Vulnerable Populations. Health Marketing Quarterly, 25, 204-216. https://doi.org/10.1080/07359680802126327

Kreps, G. L. (2012). Strategic Communication for Cancer Prevention and Control: Reaching and Influencing Vulnerable Audiences. In A. G. Georgakilas (Ed.). Cancer Prevention-From Mechanisms to Translational Benefits (pp. 376-388). London: InTech. 
https://doi.org/10.5772/31688

Masamba, L. (2015). The State of Oncology in Malawi in 2015. Malawi Medical Journal, 27, 77-78. https://doi.org/10.4314/mmj.v27i3.1

Miyawaki, R., Shibata, A., Ishii, K., \& Oka, K. (2017). News Coverage of Cancer in Japanese Newspapers: A Content Analysis. Health Communication, 32, 420-426. https://doi.org/10.1080/10410236.2016.1138391

Msyamboza, K., Dzamalala, C., Mdokwe, C., Kamiza, S., Lemerani, M., Dzowela, T., \& Kathyola, D. (2012). Burden of Cancer in Malawi; Common Types, Incidence and Trends: National Population-Based Cancer Registry. BMC Research Notes, 5, 149. https://doi.org/10.1186/1756-0500-5-149

Mughogho, L. (2015). Cases of Cancer Increasing in Malawi. Malawi 24. https://malawi24.com/2015/11/30/cases-of-cancer-feared-to-be-increasing-in-malawi

Mwafongo, A. A., Rosenberg, N. E., Ng'ambi, W., Werner, A. B., Garneau, W. M., Joe Gumulira, J., Phiri, S., \& Hosseinipour, M. C. (2014). Treatment Outcomes of AIDSAssociated Kaposi's Sarcoma under a Routine Antiretroviral Therapy Program in Lilongwe, Malawi: Bleomycin/Vincristine Compared to Vincristine Monotherapy. PLoS ONE, 9, e91020. https://doi.org/10.1371/journal.pone.0091020

Naveena, M. (2015). Importance of Mass Media in Communicating Health Messages: An Analysis. IOSR Journal of Humanities and Social Science (IOSR-JHSS), 20, 36-41.

Nkhoma, M. (2015). Cancer Cases on the Rise in Malawi Wary Medical Expert. Nyasa Times.

http://www.nyasatimes.com/cancer-cases-on-the-rise-in-malawi-wary-medical-expert

Nyasa Times (2013). Delays in Early Cancer Diagnosis Fuel Cancer Deaths in Malawi. Nyasa Times.

http://www.nyasatimes.com/delays-in-early-cancer-diagnosis-fuel-cancer-deaths-in-m alawi

Okorie, N. (2011). Mass Media Strategies for Creating Awareness of Breast Cancer. Public Knowledge Journal, 3, 1-18.

Oleniacz, L. (2016). Researchers Launch Breast Cancer Screening Pilot in Malawi. UNC Lineberger. https://unclineberger.org/news/breast-malawi

Petersen, P. E. (2009). Oral Cancer Prevention and Control-The Approach of the World Health Organization. Oral Oncology, 45, 454-460.

https://doi.org/10.1016/j.oraloncology.2008.05.023

Slater, M. D., Long, M., Bettinghaus, E. P., \& Reineke, J. B. (2008). Newspaper Coverage of Cancer in the United States: A National Sample of Newspapers, Television, and Magazines. Journal of Health Communication, 13, 523-537. https://doi.org/10.1080/10810730802279571

Stryker, J. E., Moriarty, C. M., \& Jensen, J. D. (2008). Effects of Newspaper Coverage on Public Knowledge about Modifiable Cancer Risks. Health Communication, 23, 380-390. https://doi.org/10.1080/10410230802229894

The World Bank (2018). Malawi Data. Washington DC: The World Bank. http://data.worldbank.org/country/malawi

Williamson, J. M., Jones, I. H., \& Hocken, D. B. (2011). How Does the Media Profile of Cancer Compare with Prevalence? Annals of the Royal College of Surgeons of England, 93, 9-12. https://doi.org/10.1308/003588411X12851639106954

Wisdom, J., \& Creswell, J. W. (2013). Mixed Methods: Integrating Quantitative and Qualitative Data Collection and Analysis While Studying Patient-Centered Medical Home Models (pp. 1-5). PCMH Research Methods Series 13. 